\title{
Synchronous adenocarcinomas of the colon presenting as synchronous colocolic intussusceptions in an adult
}

\author{
Chuang-Wei Chen ${ }^{1,2}$, Chieh-Wen Lai ${ }^{2,3}$ and Koung-Hong Hsiao ${ }^{1,2^{*}}$
}

\begin{abstract}
Intussusception is uncommon in adults. To our knowledge, synchronous colocolic intussusceptions have never been reported in the literature. Here we described the case of a 59-year-old female of synchronous colocolic intussusceptions presenting as acute abdomen that was diagnosed by $C T$ preoperatively. Laparotomy with radical right hemicolectomy and sigmoidectomy was undertaken without reduction of the invagination due to a significant risk of associated malignancy. The final diagnosis was synchronous adenocarcinoma of proximal transverse colon and sigmoid colon without lymph nodes or distant metastasis. The patient had an uneventful recovery. The case also emphasizes the importance of thorough exploration during surgery for bowel invagination since synchronous events may occur.
\end{abstract}

Keywords: Intussusception, Colon, Synchronous

\section{Background}

Intussusception accounts for only 1 to $5 \%$ of intestinal obstructions in adults [1]. Intussusception occurs most commonly in the small bowel, and colonic intussusception accounts for 15 to $27 \%$ of its occurrence [2-4]. Synchronous intussusception occurs even more rarely, and is only sporadically reported in the literature.

\section{Case presentation}

A 59-year-old woman presented with an eight-hour history of progressive abdominal pain and vomiting. She had occasionally experienced abdominal pain, diarrhea, and rectal bleeding over the past 2 years. Her past medical history included hysterectomy due to uterine myoma for 10 years. At the emergency department, she was alert and appeared to be in moderate distress. Her vital signs were stable and her temperature was $37.2^{\circ} \mathrm{C}$. On physical examination, her abdomen was soft but moderately tender to palpation. Digital rectal examination did not

\footnotetext{
* Correspondence: cathy166@gmail.com

'Division of Colon and Rectal Surgery, Department of Surgery, Buddhist Tzu

Chi General Hospital, No.289, Jianguo Rd., Sindian City, Taipei County 231, Taiwan (R.O.C.)

${ }^{2}$ School of Medicine, Tzu Chi University, Hualien, Taiwan

Full list of author information is available at the end of the article
}

reveal any mass or blood. Laboratory test results showed anemia (hemoglobin $9.0 \mathrm{~g} / \mathrm{dl}$ ). Abdominal radiography was unremarkable. Due to her progressively worsening abdominal pain, computer tomography $(\mathrm{CT})$ of the abdomen was performed and the result revealed synchronous colocolic intussusceptions at the rectosigmoid junction and proximal transverse colon, as well as ovarian cystic lesions (Figure 1A-C). The intussusception was indicated by the characteristic sign of edematous bowel wall and mesentery within the lumen. Synchronous intussusceptions were identified by laparotomy. Radical right hemicolectomy and sigmoidectomy were undertaken because of the high risk of malignant etiology in the colonic intussusception. Left oophorocystectomy was also performed (Figure 2). No reduction of the invagination was attempted due to the high risk of malignant pathology. The final diagnosis was synchronous moderately differentiated adenocarcinoma of the proximal transverse colon and sigmoid colon, tumor, node, metastasis (TNM) stage, T3, N0, without distant metastasis. Twenty lymph nodes were retrieved in the specimen from the right colectomy and twelve nodes in the specimen from sigmoidectomy. The pathology analysis showed the specimen from the oophorocystectomy to be a benign simple cyst. The patient had an uneventful recovery. She

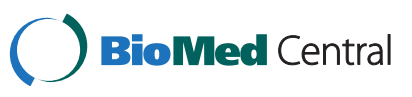



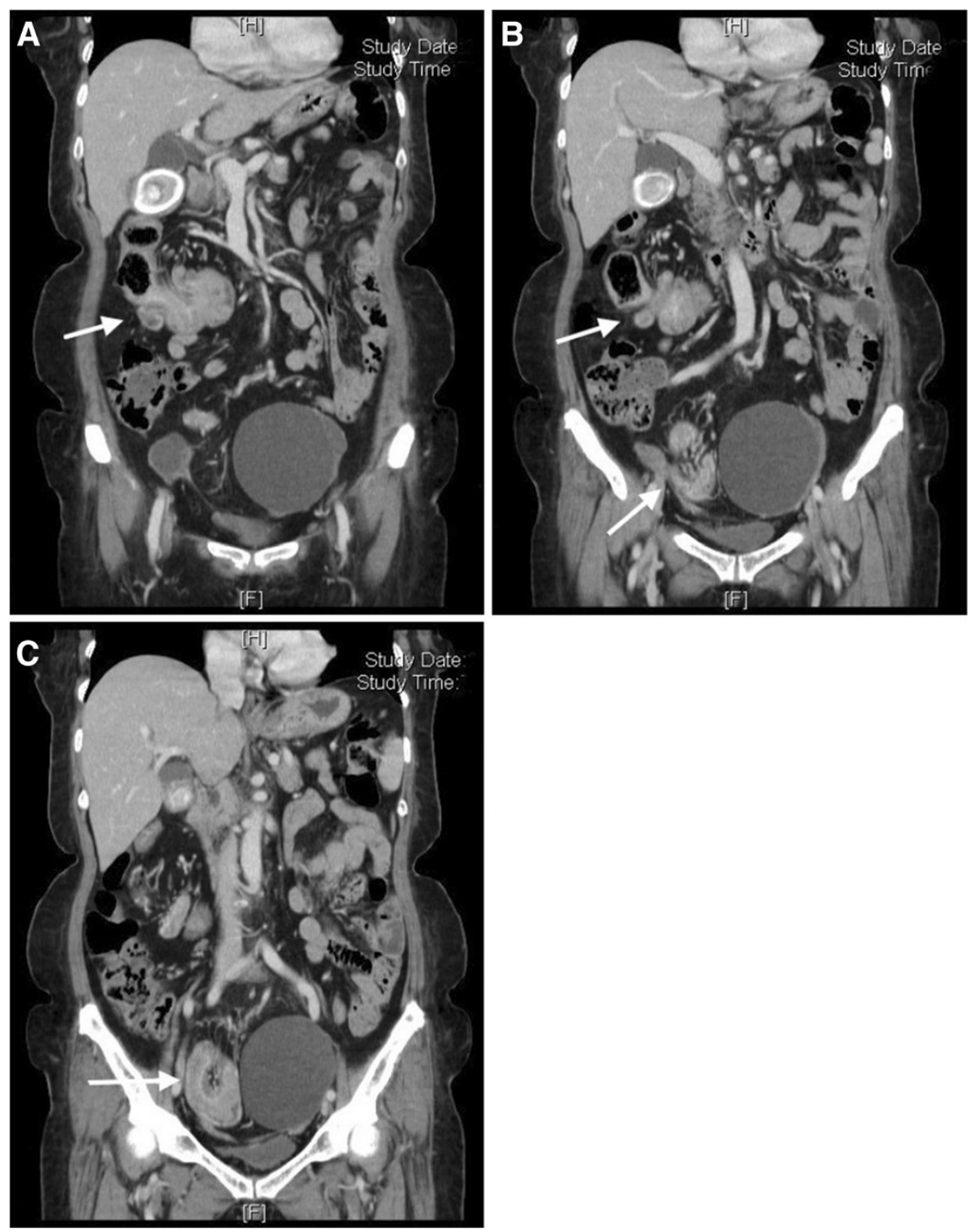

Figure 1 Computer tomography (CT) (arrows) showed the characteristic signs of the edematous bowel wall and mesentery within the lumen at the proximal transverse colon ( $A$ and $B$ ) and the rectosigmoid junction ( $B$ and $C$ ).

received adjuvant chemotherapy with oral UFUR (Tegafur $100 \mathrm{mg}$, uracil $224 \mathrm{mg}$ ) due to high risk features of systemic recurrence of pathological disease, including positive lymphovascular invasion and perineural invasion (according to the NCCN clinical practice guidelines for oncology, V.1, 2010). No recurrent symptoms or signs were noted at follow-up after 12 months.

\section{Discussion}

Adult intussusception represents only $5 \%$ of all cases of intussusception $[5,6]$. Unlike children, more than $90 \%$ of all adult intussusceptions have pathological causes, especially colonic intussusception [7]. Malignant intussusceptions account for the majority of colonic invaginations, whereas $80 \%$ of neoplasms associated with small bowel intussusception were benign [2]. Primary colon adenocarcinoma is the most common underlying malignant lesion in colonic intussusception [2]. Due to the high malignancy rate, en bloc resection without reduction for adult colonic intussusception is advocated to prevent any potential spread of the tumor and contamination of the abdominal cavity due to incidental perforation [8,9]. Regarding benign tumors, lipoma is the most commonly pathologic lead point in both small and large bowel intussusception. The recognition of the tumor spectrum and incidence of malignances differ between small and large bowel intussusception in adults 


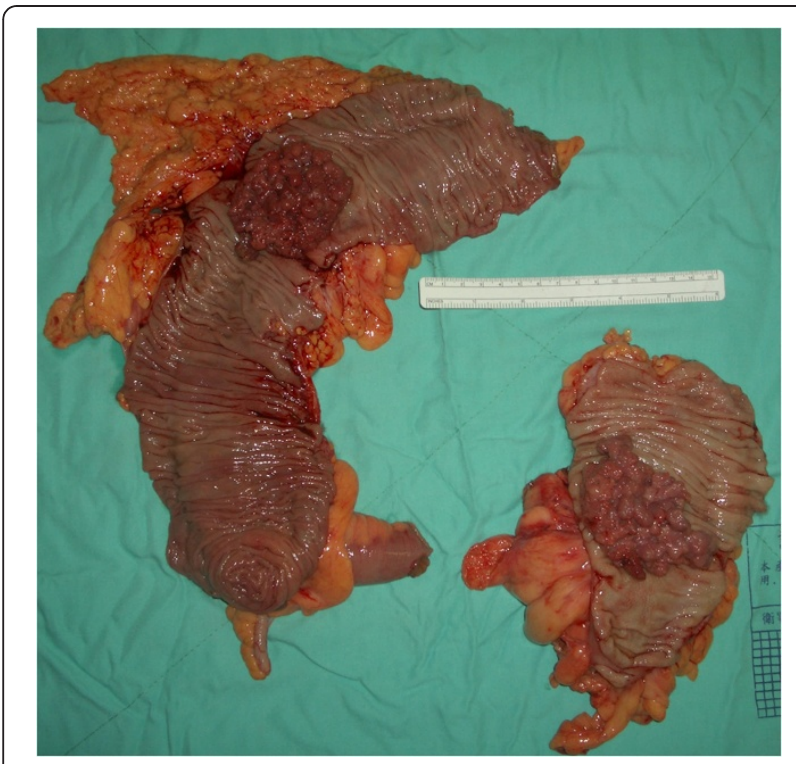

Figure 2 The surgical specimens showed synchronous tumors at the proximal transverse colon and sigmoid colon.

can help surgeons adopt appropriate surgical procedure for intussusception.

In contrast to pediatric presentation of acute intussusception, the classic triad of cramping abdominal pain, bloody diarrhea and a palpable tender mass is rare in adults [3]. The symptoms of adult intussusception are non-specific [3]. Abdominal pain is the most common presenting complaint, followed by nausea, vomiting, gastrointestinal bleeding and diarrhea [2]. Morera Ocon, et al. [4] reported that the preoperative diagnosis of invagination was made in 25/30 (83\%) of patients. However, in a review by Athanasios Marinis, et al. [3], the authors stated that variability in clinical presentation and imaging features often make the preoperative diagnosis of intussusception a challenging and difficult task. Reijene, et al. [10] reported a preoperative diagnostic rate of 50\%, while Eisen, et al. [11] reported a lower rate of $40.7 \%$.

Abdominal radiographs usually demonstrate signs of intestinal obstruction and may provide information about the site of the obstruction [3]. Upper gastrointestinal contrast series or barium enema examination may demonstrate the characteristic appearance of a coiledspring or cup-shaped filling defect [3]. Ultrasonography is considered a useful tool for the diagnosis of intussusception by an experienced observer. The typical imaging features include the target or doughnut signs on the transverse view and the pseudo-kidney sign on the longitudinal view [3]. With the growing use of CT in the diagnosis of abdominal diseases, especially for the patients presenting with acute abdomen, preoperative detection of intussusception has increased. Most studies also indicate that $\mathrm{CT}$ is the most accurate diagnostic tool for intussusception [12]. Typical features of intussusception on CT s include the pseudo-kidney, target or bulls-eye sign, or the appearance of bowel-within-bowel configuration with or without fat and mesenteric vessels. The CT scan may also define the location, the nature of the mass, its relationship to surrounding tissues and additionally, it may help in disease staging in patients in whom malignancy is the suspected cause of the intussusception $[13,14]$.

\section{Conclusions}

To our knowledge, synchronous colocolic intussusceptions have never been reported in the literature. Here we describe the first case of synchronous colocolic intussusceptions caused by synchronous adenocarcinoma of the colon diagnosed preoperatively by CT. The case also emphasizes the importance of thorough exploration during surgery for bowel invagination, since synchronous events may occur.

\section{Consent}

Written informed consent was obtained from the patient for publication of this report and any accompanying images.

\section{Competing interests \\ The authors declare that they have no competing interests.}

\section{Authors' contribution}

We declare that all the listed authors have participated actively in the study and all meet the requirements of the authorship. CWC designed the study and wrote the protocol, $\mathrm{KHH}$ performed research/study, CWL managed the literature searches and analyses, CWC wrote the first draft of the manuscript. All authors read and approved the final manuscript.

\section{Author details}

'Division of Colon and Rectal Surgery, Department of Surgery, Buddhist Tzu Chi General Hospital, No.289, Jianguo Rd., Sindian City, Taipei County 231,

Taiwan (R.O.C.). ${ }^{2}$ School of Medicine, Tzu Chi University, Hualien, Taiwan.

${ }^{3}$ Division of General Surgery, Department of Surgery, Buddhist Tzu Chi

General Hospital, Taipei Branch, Taipei, Taiwan.

Received: 11 December 2011 Accepted: 26 November 2012 Published: 15 December 2012

\section{References}

1. Azar T, Berger D: Adult intussusception. Ann Surg 1997, 226:134-138.

2. Chiang JM, Lin YS: Tumor spectrum of adult intussusception. J Surg Oncol 2008, 98:444-447.

3. Marinis A, Yiallourou A, Samanides L, Dafnios N, Anastasopoulos G, Vassiliou I, Theodosopoulos T: Intussusception of the bowel in adults: a review. World J Gastroenterol 2009, 15:407-411.

4. Morera-Ocon FJ, Hernandes-Montes E, Bernal-Sprekelsen JC: Intestinal invagination in adults: presentation of a case and a review of the Spanish literature. Cir Esp 2009, 86:358-362.

5. Begos DG, Sandor A, Modlin I: The diagnosis and management of adult intussusception. Am J Surg 1997, 73:88-94.

6. Nagorney DM, Starr MG, Mcilrath DC: Surgical management of intussusception in the adult. Ann Surg 1981, 193:230-236.

7. Huang WS, Changchien CS, Lu SN: Adult intussusception: A 12-year experience, with emphasis on etiology and analysis of risk factors. Chang Gung Med J 2000, 23:284-290. 
8. Goh BKP, Quah HM, Chow PKH, Tan KY, Tay KH, Eu KW, Ooi LL, Wong WK: Predictive factors of malignancy in adults with intussusception. World $J$ Surg 2006, 30:1300-1304.

9. Haas EM, Etter EL, Ellis S, Taylor TV: Adult intussusception. Am J Surg 2003, 186:75-76.

10. Reijnen HA, Joosten HJ, de Boer HH: Diagnosis and treatment of adult intussusception. Am J Surg 1989, 158:25-28.

11. Eisen LK, Cunningham JD, Aufses AH Jr: Intussusception in adults: institutional review. J Am Coll Surg 1999, 188:390-395.

12. Gayer G, Zissin R, Apter S, Papa M, Hertz M: Pictorial review: adult intussusception-a CT diagnosis. Br J Radiol 2002, 75:185-190.

13. Barussaud M, Regnet N, Briennon X, Kerviler BD, Pessaux P, Sharhi NK, Lehur PA, Hamy A, Leborgne J, Neel JC, Mirallie E: Clinical spectrum and surgical approach of adult intussusceptions: a multicentric study. Int I Colorectal Dis 2006, 21:834-839.

14. Erkan N, Hacryanh M, Yildirm M, Sayhan H, Vardar E, Polat AF: Intussusception in adults: an unusual and challenging condition for surgeons. Int J Colorectal Dis 2005, 20:452-456.

doi:10.1186/1477-7819-10-272

Cite this article as: Chen et al: Synchronous adenocarcinomas of the colon presenting as synchronous colocolic intussusceptions in an adult. World Journal of Surgical Oncology 2012 10:272.

\section{Submit your next manuscript to BioMed Central and take full advantage of:}

- Convenient online submission

- Thorough peer review

- No space constraints or color figure charges

- Immediate publication on acceptance

- Inclusion in PubMed, CAS, Scopus and Google Scholar

- Research which is freely available for redistribution 